\title{
Evaluation of the Thermal Comfort of Ceramic Floor Tiles
}

\author{
Carmeane Effting ${ }^{\mathrm{a} *}$, Saulo Güths ${ }^{\mathrm{b} *}$, Orestes Estevam Alarcon ${ }^{\mathrm{a}}$ \\ à Programa de Pós-Graduação em Ciência e Engenharia de Materiais, \\ Universidade Federal de Santa Catarina - UFSC, Departamento de Engenharia Mecânica, \\ Campus Universitário-Trindade, CP 476, 88040-900 Florianópolis - SC, Brazil \\ ${ }^{\mathrm{b}}$ Universidade Federal de Santa Catarina - UFSC, Departamento de Engenharia Mecânica, \\ Laboratório de Meios Porosos e Propriedades Termofísicas, Campus Universitário-Trindade, \\ CP 476, 88040-900 Florianópolis - SC, Brazil
}

Received: March 21, 2007; Revised: June 23

\begin{abstract}
In places where people are bare feet, the thermal sensation of cold or hot depends on the environmental conditions and material properties including its microstructure and crustiness surface. The uncomforting can be characterized by heated floor surfaces in external environments which are exposed to sun radiation (swimming polls areas) or by cold floor surfaces in internal environments (bed rooms, path rooms). The property named thermal effusivity which defines the interface temperature when two semi-infinite solids are putted in perfect contact. The introduction of the crustiness surface on the ceramic tiles interferes in the contact temperature and also it can be a strategy to obtain ceramic tiles more comfortable. Materials with low conductivities and densities can be obtained by porous inclusion are due particularly to the processing conditions usually employed. However, the presence of pores generally involves low mechanical strength. This work has the objective to evaluate the thermal comfort of ceramics floor obtained by incorporation of refractory raw materials (residue of the polishing of the porcelanato) in industrial atomized ceramic powder, through the thermal and mechanical properties. The theoretical and experimental results show that the porosity and crustiness surface increases; there is sensitive improvement in the comfort by contact.
\end{abstract}

Keywords: ceramic tiles, thermal properties, thermal comfort, porosity

\section{Introduction}

The ceramic industry is constantly seeking to the market amplification for the sector and perfecting the quality of the products and to increase the variety of carried out functions. The technology of obtaining of ceramic floor tiles that provide thermal comfort to the contact assists market niches little explored, as hot environments (swimming pools areas) and cold environments (bedrooms, bathrooms).

Ceramic floor tiles are widely used in buildings, possessing technical and aesthetic functions. However the technical function becomes very important in constructions with human occupation where the thermal comfort is requested. In that way, we can verify that in a lot of situations the ceramic tiles don't offer appropriate thermal comfort.

The human body can be considered as a thermal machine that generates between 100 and $1000 \mathrm{~W}$ of heat, depending on the performed activity. The heat generated by the human body must be dissipated to maintain constant the human body temperature (considered normal between 35 and $37^{\circ} \mathrm{C}$ ). Thermal regulator mechanisms are responsible for this task. Many elements that contribute to comfort are characterized by the physiological and psychological response intensities of an individual to the environment ${ }^{11}$. The main environmental variables are air temperature, relative humidity, wind speed and radiant temperature ${ }^{1,4}$.

However, people can be subjected to localized discomfort, for example, bare feet in contact with a hot (external floor surfaces that are exposed to solar radiation) or cold floor (internal floor surfaces) where the thermal sensation depends on the environmental conditions and material properties including its microstructure and crustiness surface.
The uncomforting can be characterized by heated floor surfaces in external environments which are exposed to sun radiation (swimming polls areas) or by cold floor surfaces in internal environments (bed rooms, path rooms). The thermal sensation is related to skin temperature, in this case, when the surfaces of the feet are in contact with the pavement. They are few works that evaluate the discomfort for contact, being more gone back to safety's condition (NR 15, 1978 and PD 6504, 1983). The contact temperature can be correlated by a property named "thermal effusivity" which defines the interface temperature when two solids are putted in contact. As lower is the thermal effusivity more comfortable is the ceramic floor tile.

The thermal effusivity is correlated directly with thermal conductivity and material density. The interface temperature also depends on the contact resistance, highly dependent of the crustiness surface.

Materials with low conductivities and densities can be obtained by porous inclusion. Generally, thermal conductivity of porous materials decreases as porosity increases ${ }^{8}$. Porosity of ceramic materials usually is related to processing conditions used. However, high porosity generally implies low mechanical strength. It is possible to obtain porous ceramics with high mechanical strength and chemical resistance by appropriately combining raw materials and processing techniques. High refractoriness and high structural uniformity with favorable thermal properties for a given application also can be achieved.

There are many methods of obtaining porous ceramics. An early method that remains in wide use is incorporation of organic products in the ceramic body that are later removed during the firing step. The resulting porosity depends on the size of the organic particles 
used. Other methods have advantages and potential application. Processing control and, consequently, final material properties are a general problem ${ }^{7}$.

In this work, porous ceramic tiles were obtained by pressing an industrial atomized ceramic powder incorporated with various weight fractions $(10,20,30,40,50$ and $70 \%)$ of refractory raw material (residue from porcelainized stoneware tile polishing). Thermal properties (effusivity and conductivity), and mechanical properties (mechanical strength) were also evaluated. The ceramic tiles were exposed to solar radiation, being obtained the maxim superficial temperature. Parallel the ceramic tiles were submitted to a sudden contact with a cold source, being obtained by extrapolation the contact temperature between the pavement and the human bare feet with different crustiness.

\section{Experiments}

The chemical composition of the ceramic body used in this work has been determined (Table 1). The constituent oxides are typical of ceramic bodies used for the manufacture of ceramic floor tiles.

In the compaction technique of the industrial atomized ceramic powder incorporated with residue, the residue will be the natural porous formers. The mixtures with various weight fractions $0,10,20,30,40$, 50,75 and $100 \%$ of residue (M, MAR 10, MAR 20, MAR 30, MAR 40, MAR 50 and MAR 70), were homogenized previously in a mill, dried at $110{ }^{\circ} \mathrm{C}$ for 24 hours and prepared with $6,7,8,9,10,11$ and $12 \%$ humidity respectively. Soon after, the obtained mixtures were compacted at $30 \mathrm{MPa}$ with nominal dimensions of $58 \times 126 \times 10 \mathrm{~mm}$.

The compacted samples were dried at $110^{\circ} \mathrm{C}$ for 24 hours and subsequently fired in a muffle furnace at $1170^{\circ} \mathrm{C}$ (landing of 3 minutes and with a heating and cooling rate of $10^{\circ} \mathrm{C} / \mathrm{min}$ ).

\section{Results and Discussion}

The morphology of the two materials were studied through the scanning electron microscopy (SEM) technique. According to the SEM micrographs and performed measurements, the atomized powder is characterized by a heterogeneity in the shape and size of the granules as illustrated in the Figures 1 and 2 with a magnification of $30 \mathrm{x}$. Moreover, the granules of the atomized powder are characterized by spherical particles due to the atomization process and with medium diameters ranging from 300 to $600 \mu \mathrm{m}$ (Figure 1).

Figure 2 shows the SEM micrograph of the residue. It can be seen from figure that the particles present much finer granulation than the atomized powder. The energy-dispersive spectrometry (EDS) technique was used to verify the chemical composition of these agglomerates, where the found elements were $\mathrm{Si}, \mathrm{Al}, \mathrm{Mg}, \mathrm{Fe}$ e K.

The SEM micrographs for a ceramic sample compacted with the incorporation of 0 and $40 \%$ of residue are presented in the Figures 3 and 4 , respectively. For an amplification of 50x, it can be seen that over the normal porosity usually observed in typical ceramic floor

Table 1. Composition of ceramic body.

\begin{tabular}{lc}
\hline Oxides & wt. $(\%)$ \\
\hline $\mathrm{SiO}_{2}$ & 67.35 \\
$\mathrm{Al}_{2} \mathrm{O}_{3}$ & 19.79 \\
$\mathrm{Fe}_{2} \mathrm{O}_{3}$ & 2.52 \\
$\mathrm{Na}_{2} \mathrm{O}$ & 0.15 \\
$\mathrm{~K}_{2} \mathrm{O}$ & 4.13 \\
$\mathrm{TiO}_{2}$ & 0.92 \\
$\mathrm{MgO}$ & 2.00 \\
$\mathrm{CaO}$ & 2.32 \\
\hline
\end{tabular}

tiles there is also porosity provided by the residue. The amount and size of pores increases when the amount of residue is increased.

Table 2 shows the medium values of the mechanical and physical properties measures for each five ceramic samples constituted of atomized ceramic powder incorporated with residue weight fractions. The presence of pores implicated in decrease of the mechanical resistance.

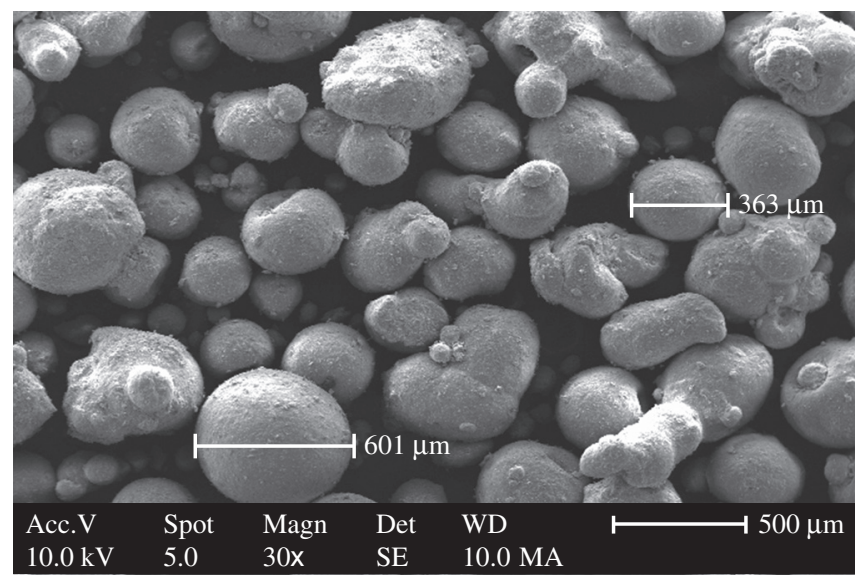

Figure 1. SEM micrograph of atomized ceramic powder. Magnification: $30 \mathrm{x}$.

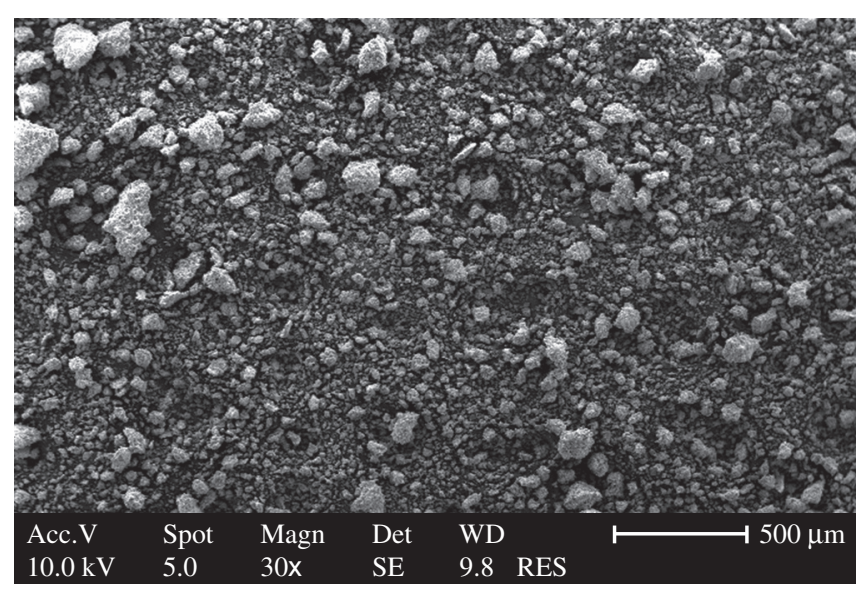

Figure 2. SEM micrograph of residue Magnification: 30x.

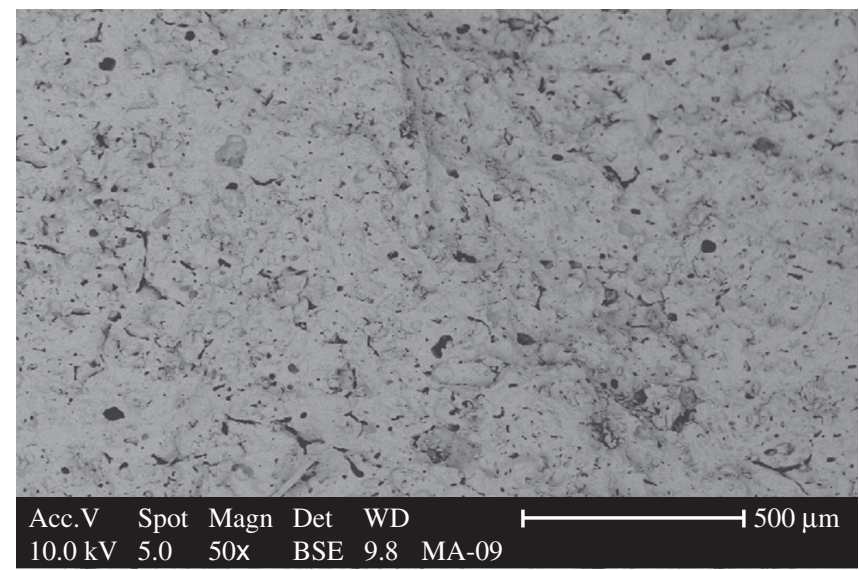

Figure 3. SEM micrograph of a ceramic sample atomized powder. Magnification: 50x. 
A high fraction of residues is required of the thermal point of view (smaller effusivity), however the ceramic floor tile will be more fragile. It can be verified from with relationship to the physical properties that the apparent density decreases as incorporation of the residues increases because there is an increase of the porosity. From observation of the real density, that represents the solid ceramic matrix density, it can be verified that so much the atomized powder as the residue possesses very similar densities.

\subsection{Thermal characterization}

The different samples were fixed with mortar on a standard pavement and exposed to sun radiation for the foot-pavement contact test. After the complete cure (three weeks) the values of the surface temperature were registered $\left(\mathrm{T}_{\text {sun }}\right)$. This surface temperature was measured by a plane thermocouple, type T, as well as the soil temperature, base of the pavement and ambient air. The control system was monitored for 24 hours during a period of two weeks to obtain the maximum values, correlated with the radiation values and air temperature.

Thus, the maxim surface temperature of a commercial ceramic floor tile GEB (crustiness and smooth) and of the ceramic tiles manufactured exposed to sun radiation for a day typical, cloudless and of strong insulation were registered.

The surface of a ceramic floor tile exposed to sun radiation change heat with the environment for convection and radiation. The construction materials are selective to the sun radiation of short wave and

Table 2. Results obtained for ceramic samples with and without residue incorporation.

\begin{tabular}{lcccc}
\hline \multirow{2}{*}{ Samples } & \multicolumn{4}{c}{ Experimental values } \\
\cline { 2 - 5 } & MRF (MPa) & $\rho_{\mathrm{a}}\left(\mathrm{kg} \cdot \mathrm{m}^{-3}\right)$ & $\rho_{\mathrm{r}}\left(\mathrm{kg} \cdot \mathrm{m}^{-3}\right)$ & $\mathrm{P}(\%)$ \\
\hline M (without & 33 & 2307 & 3235 & 29 \\
residue) & & & & \\
MAR 10 & 25 & 2130 & 3176 & 33 \\
MAR 20 & 21 & 1990 & 3085 & 36 \\
MAR 30 & 16 & 1845 & 2980 & 38 \\
MAR 40 & 13 & 1680 & 2967 & 43 \\
MAR 50 & 13 & 1560 & 2930 & 47 \\
MAR 75 & 9 & 1100 & 3180 & 65 \\
RES & 10 & 1110 & 3127 & 64 \\
\hline
\end{tabular}

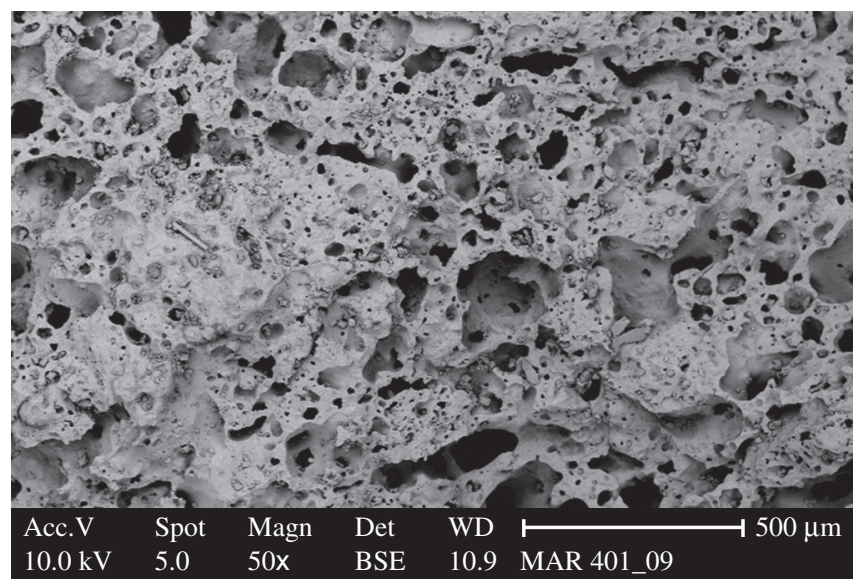

Figure. 4. SEM micrograph of a ceramic sample with $40 \%$ residue. Magnification: 50x. the principal determinant of this characteristic is your surface color. Clearer colors result in a smaller surface temperature and therefore they could present larger thermal comfort for the user. Like this, in a first moment, we can say that clear ceramic floor tiles would be appropriate in relation to the thermal comfort. However, in this case, we would not be considering the individual's visual comfort. This ceramic tile, for being clearer, it can be dazzling under direct insulation.

Thermal conductivity measurement was conducted according to ISO 8301 (1991). For this test, considering the homogeneous sample, it is possible to determine the thermal conductivity through the Equation 1 where $\lambda$ is the conductivity, $W /(m . K)$; $R$ is thermal resistance, $\mathrm{m}^{2} \mathrm{~K} / \mathrm{W}$ and $\mathrm{L}$ is the material thickness, $\mathrm{m}$ :

$$
\lambda=\frac{\mathrm{L}}{\mathrm{R}}
$$

The thermal conductivity of a porous material is strongly dependent of the material density (or fraction of pores). The theoretical model proposed by Aivazov and Domashnev ${ }^{2}$, well correlates the thermal conductivity of porous ceramics with the porosity according to Equation 2:

$$
\frac{\lambda}{\lambda_{\mathrm{O}}}=\frac{1-\mathrm{P}}{1+\mathrm{nP}^{2}}
$$

where $\lambda$ is the thermal conductivity of a porous ceramic body, $\lambda_{\mathrm{o}}$ is the thermal conductivity of a porous free ceramic body, $\mathrm{P}$ is the volume fraction of porous, and $\mathrm{n}$ is a constant. Sugawara and Yoshizawa (1962) measured the thermal conductivity of a ceramic tile at $70{ }^{\circ} \mathrm{C}$. According to their measurements n corresponds to 3 and $\lambda_{\mathrm{o}}=1.65 \mathrm{~W} / \mathrm{m}$.K. Considering that there is no specific heat change with porous inclusions and that the air density can be scorned face to the ceramic matrix density, Equation 2 can be written in terms of effusivity $(\varepsilon)$ according to Equation 3:

$$
\frac{\varepsilon}{\varepsilon_{\mathrm{o}}}=\frac{1-\mathrm{P}}{\sqrt{1-\mathrm{nP}^{2}}}
$$

where $\varepsilon$ is the thermal effusivity of a porous ceramic body and $\varepsilon_{0}$ the thermal effusivity of a porous free ceramic body, being $\varepsilon$ defined by Equation 4:

$$
\varepsilon=\sqrt{ } \lambda \rho c
$$

where $\rho$ is the density, $\mathrm{kg} \cdot \mathrm{m}^{-3}$ and $\mathrm{c}$ is the specific heat, $\mathrm{J} /(\mathrm{kg} . \mathrm{K})$.

The porosity effect on thermal conductivity and effusivity for ceramic bodies with residue incorporation has been determined (Figures 5 and 6). The thermal conductivity and effusivity depend

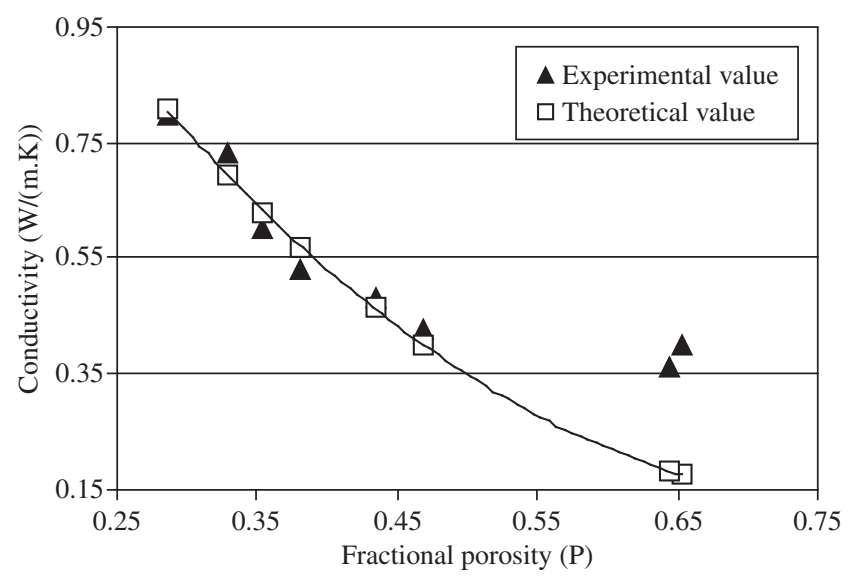

Figure 5. Measured and theoretical thermal conductivities as a function of porosity. 
on porosity; i.e., they decrease as the porosity increases by changing the residue content from 0 to $100 \mathrm{wt}$. (\%).

The experimentally obtained results have been compared with theoretical model proposed by Aivazov and Domashnev (1968) for thermal conductivity, according with the Equation 2. Good correlation occurs in the porosity interval from 0 to $50 \%$ for $n=4.5$ and $\lambda_{\mathrm{o}}=1.6 \mathrm{~W} /(\mathrm{m} . \mathrm{K})$. However, in the porosity interval studied (from 0 to $100 \%)$, in this case, are not well correlated with the theoretical model, because there is more porosity than solid ceramic matrix.

Besides the ceramic tiles manufactured, the samples obtained of the commercial floor tile GEB (crustiness and smooth) were also evaluated. This ceramic floor tiles presents a crustiness surface, with a distance between picks and value of approximately $0.55 \mathrm{~mm}$. One of the samples was extracted of the original ceramic floor tile and other obtained through the polishing of the crustiness of this same tile.

In these tests (Figure 7), a fine film of latex was inserted (thickness $=0.1 \mathrm{~mm}$ ) among the sample superior surface and the superior fluxmeter to simulate the contact resistance between the barefoot and the ceramic floor tile evaluated. Thus, the difference among the contact resistances of the crustiness ceramic tiles $\left(\mathrm{R}_{\text {crustiness }}\right)$ and smooth ceramic tiles $\left(\mathrm{R}_{\text {smooth }}\right)$ indicate the contact resistance $\left(\mathrm{R}_{\text {contact }}\right)$. It was still possible to obtain the apparent thermal conductivity of this contact, according to Table 3.

The variable of interest that happens in the contact of a barefoot with a hot ceramic floor tile (or cold) it is the maximum temperature (or low). Given the difficulty of obtaining repeatability in the tests using a person's foot, an apparatus was idealized (Figure 8) where the same was simulated by a double glove of latex (thickness $=0.65 \mathrm{~mm}$ )

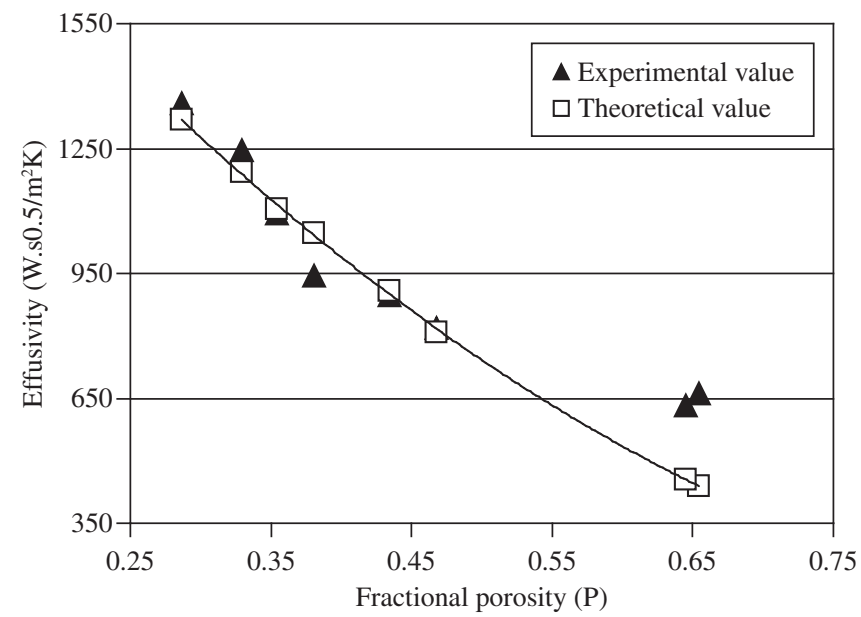

Figure 6. Measured and theoretical thermal effusivities as a function of porosity.

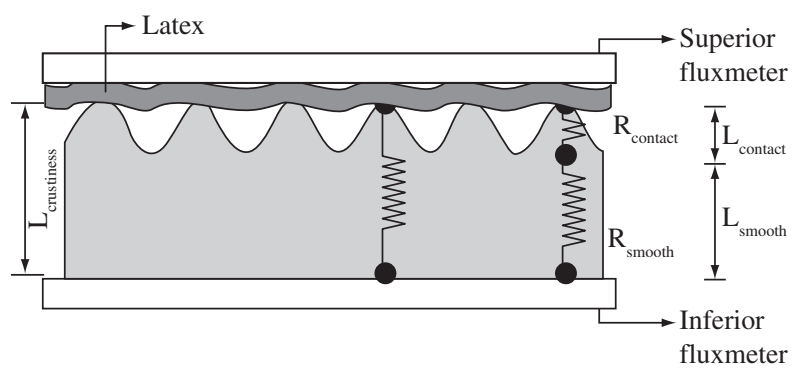

Figure 7. Schematic illustration of the conductivity test. filled out with a mixture of water and melting ice, maintained constant temperature at $0{ }^{\circ} \mathrm{C}$.

In this glove a plane thermocouple was fixed (thickness $=0.1 \mathrm{~mm}$ ) to determine the maxim temperature in the sudden contact with a ceramic floor tile isothermal to the environment temperature.

The temperature of the ceramic floor tile was also measured by a plane thermocouple (thickness $=0.1 \mathrm{~mm}$ ). This experimental apparatus was elaborated to evaluate the maximum temperature of the feet surfaces when in contact with the pavement along the time, as shown in the Figure 9.

It can be observed that this temperature reaches a maximum value $\left(\Delta \mathrm{T}_{\max }\right)$ that is the temperature of interest in this analysis. Extracting the value of the maxim variation of the contact temperature $\left(\Delta \mathrm{T}_{\max }\right)$, a rate (f) was determined among this variation (glove-tile) and the tile temperature $\left(\mathrm{T}_{\text {initial }}\right)$, obtained by Equation 5 :

$$
\mathrm{f}=\frac{\Delta \mathrm{T}_{\max }}{\mathrm{T}_{\text {initial }}}
$$

The foot-pavement contact temperature $\left(\mathrm{T}_{\text {contact estimated }}\right)$ it can be estimated starting from the previous results, being considered the foot to a temperature of $34{ }^{\circ} \mathrm{C}$ in contact with the tiles exposed to

Table 3. Apparent conductivity and thermal resistance in the contact for ceramic tiles.

\begin{tabular}{lccc}
\hline Samples & $\begin{array}{c}\text { Thickness } \\
(\mathrm{mm})\end{array}$ & $\begin{array}{c}\text { Apparent thermal } \\
\text { conductivity } \\
(\mathrm{W} / \mathrm{m} . \mathrm{K})\end{array}$ & $\begin{array}{c}\text { Thermal resistance } \\
(\mathrm{W} / \mathrm{K})\end{array}$ \\
\hline $\begin{array}{l}\text { Tile GEB } \\
\text { (crustiness) }\end{array}$ & $7.70 \times 10^{-3}$ & 0.48 & $16.04 \times 10^{-3}$ \\
$\begin{array}{l}\text { Tile GEB } \\
\text { (smooth) }\end{array}$ & $7.15 \times 10^{-3}$ & 0.72 & $9.90 \times 10^{-3}$ \\
Contact & $0.55 \times 10^{-3}$ & 0.09 & $6.14 \times 10^{-3}$ \\
\hline
\end{tabular}

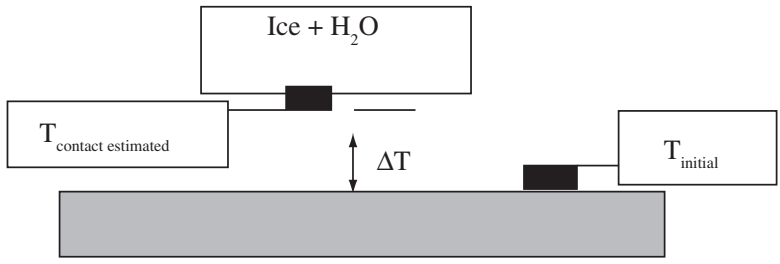

Figure 8. Schematic illustration of the foot-pavement.

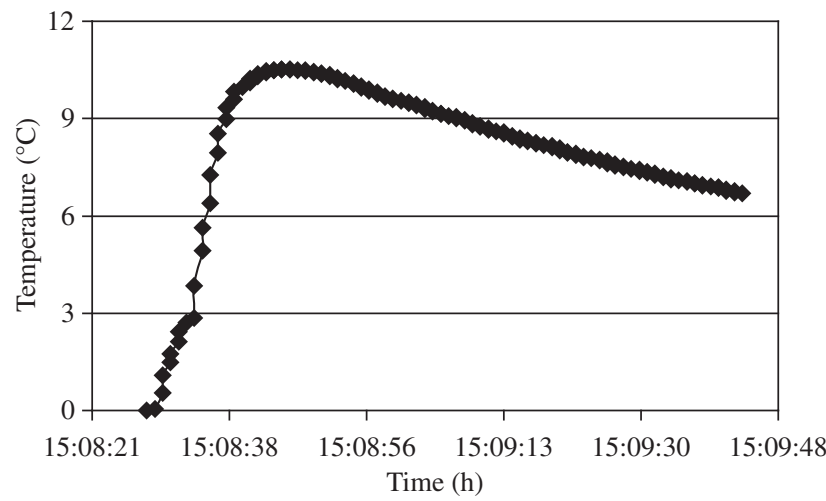

Figure 9. Squematic illustration of the contact temperature (glove - smooth tile GEB) along the time. 
sun radiation to presented surface temperatures. Considering that the variation of temperature of contact foot-pavement is similar to the obtained results (contact temperature glove-tile), the temperature of contact foot-tile is defined by Equation 6:

$$
\mathrm{T}_{\text {contact estimated }}=34+\mathrm{f}\left(\mathrm{T}_{\text {sun }}-34\right)
$$

The two samples of the tile GEB (crustiness and smooth) were evaluated to a surface temperature of the tile measured through the apparatus elaborated. Soon after, it was made the sudden contact of a barefoot (glove) under the tiles, registering the contact temperature (glove-tile) along the time. As expected, the smooth and crustiness ceramic floor tile reached a temperature of contact of 40.5 and $37.8^{\circ} \mathrm{C}$, respectively. Already for the ceramic samples manufactured, M (without residue, porosity of 29\%) and MAR 40 (40\% of residue, porosity equal to $43 \%$ ) the temperature was of approximately 42.8 and $39.1^{\circ} \mathrm{C}$. Soon, the pavement assembled using ceramic floor tile MAR 40 achieved a temperature of $\sim 4^{\circ} \mathrm{C}$ lower than that achieved using ceramic floor tile $\mathrm{M}$. Even so, a small improvement in the comfort level by contact was obtained. Table 4 shows the surface temperature of the samples exposed to sun radiation $\left(\mathrm{T}_{\text {sun }}\right)$, the initial temperature of the tiles $\left(\mathrm{T}_{\text {initial }}\right)$, maximum values of glove-tile contact temperature $\left(\Delta \mathrm{T}_{\max }\right)$ and the glove-tile contact temperature $\left(\mathrm{T}_{\text {contact estimated }}\right)$ obtained through the apparatus elaborated.

If the foot and the pavement are considered as semi-infinite solids, initially at uniform temperatures $\mathrm{T}_{\text {foot }}$ and $\mathrm{T}_{\text {sun }}$ are placed in contact they achieve equilibrium. The foot can be considered as having a thermal conductivity of $0.37 \mathrm{~W} / \mathrm{m} . \mathrm{K}$, density of $1000 \mathrm{~kg} \cdot \mathrm{m}^{-3}$ and specific heat of $1000 \mathrm{~J} / \mathrm{kgK}$. Therefore, the resulting thermal effusivity is $600 \mathrm{Ws}^{0,5} / \mathrm{m}^{2} \mathrm{~K}^{4}$.

If contact resistance is ignored, the temperature contact theoretical becomes constant with time and can be expressed by Equation 7:

$$
\mathrm{T}_{\text {contact theoretical }}=\frac{\varepsilon_{\text {foot }} \mathrm{T}_{\text {foot }}+\varepsilon_{\text {sun }} \mathrm{T}_{\text {sun }}}{\varepsilon_{\text {foot }}+\varepsilon_{\text {sun }}}
$$

Thus, the effusivity is a pondering factor which determine if the contact temperature $\left(\mathrm{T}_{\text {contact }}\right)$ will be close to $\mathrm{T}_{\text {foot }}$ (if $\varepsilon_{\text {sun }}>\varepsilon_{\text {foot }}$ ) or to $\mathrm{T}_{\text {sun }}$ (if $\varepsilon_{\text {sun }}<\varepsilon_{\text {foot }}$ ). The ceramic materials (porous or non-porous one) show specific heat values very close (about $1 \mathrm{~kJ} / \mathrm{kg} . \mathrm{K}$ ). Consequently, the ef-

Table 4. Estimate of the contact temperature (foot-tile).

\begin{tabular}{lrrrrc}
\hline \multicolumn{1}{c}{ Samples } & $\begin{array}{c}\mathrm{T}_{\text {initial }} \\
\left({ }^{\circ} \mathrm{C}\right)\end{array}$ & $\begin{array}{c}\Delta \mathrm{T}_{\max } \\
\left({ }^{\circ} \mathrm{C}\right)\end{array}$ & $\mathrm{f}$ & $\begin{array}{c}\mathrm{T}_{\text {sun }} \\
\left({ }^{\circ} \mathrm{C}\right)\end{array}$ & $\begin{array}{c}\mathrm{T}_{\text {contact estimated }} \\
\left({ }^{\circ} \mathrm{C}\right)\end{array}$ \\
\hline GEB (smooth) & 26.7 & 10.52 & 0.39 & 50.4 & 40.5 \\
GEB (crustiness) & 24.1 & 5.62 & 0.23 & 50.4 & 37.8 \\
M & 24.0 & 9.45 & 0.39 & 56.3 & 42.8 \\
MAR 10 & 23.6 & 8.72 & 0.37 & 54.1 & 41.4 \\
MAR 20 & 24.4 & 7.92 & 0.32 & 54.4 & 40.6 \\
MAR 30 & 24.5 & 7.07 & 0.29 & 55.0 & 40.0 \\
MAR 40 & 23.9 & 5.85 & 0.25 & 55.0 & 39.1 \\
MAR 50 & 24.1 & 5.82 & 0.24 & 55.0 & 39.0 \\
MAR75 & 24.3 & 4.80 & 0.20 & 55.0 & 38.0 \\
RES & 24.3 & 3.50 & 0.14 & 55.0 & 37.0 \\
\hline
\end{tabular}

fusivity depends on the thermal conductivity and material's density.

A relationship has been determined between the measured temperature under the foot surface and the contact theoretical temperature (Table 5). The relationship verifies a significant difference between the experimental and theoretical values.

\section{Conclusions}

The localized uncomforting sensation of a barefoot with a surface cold or hot is related with the interface temperature. This temperature is correlated traditionally with the thermal effusivity of the bodies in contact. The effusivity decrease as the porosity increases, generated by incorporation of residue from porcelainized stoneware tile polishing in industrial atomized ceramic powder. The incorporation of pores reduced the mechanical resistance.

The theoretical model proposed by Aivazov and Domashnev (1968) well correlates the experimental thermal conductivity obtained for the samples ceramic with various residue percentages for the interval of the porosity among 0 to $50 \%$ and for the value of $n=4.5$ and $\lambda_{\mathrm{o}}=1.6 \mathrm{~W} / \mathrm{m} . \mathrm{K}$. However, in the porosity interval studied (from 0 to $100 \%$ ), in this case, because there is more porosity than solid ceramic matrix. Therefore, it is necessary we use other model that considers the ceramic as a composite since we are incorporating the residue to the industrial atomized ceramic powder and these materials possess different conductivities.

The experimental apparatus elaborated for the contact test of a barefoot with pavement was coherent and important for the study of the evaluation of the thermal comfort

because the theoretical and experimental temperature of interface decreases with the reduction of the thermal effusivity and improve the comfort by contact. It can verify a significant difference between the experimental and theoretical values. Among the possible causes it can mention the uncertainty value of the foot thermal properties, the foot-pavement contact resistance and the semi-infinite solid model, as well as the measurement uncertainties.

The methodology of measurement of the thermal resistance of the crustiness ceramic floor tile was effective reproducing in a simple way the contact of the barefoot with any surface. It was proved that the introduction of a resistance of additional contact (crustiness surface) produces a reduction in the contact temperature. Thus the two strategies could be combined (porous ceramic tile and crustiness), producing tiles with larger thermal comfort, so much for the heat as for the cold. Other aspects still need to be studied better with relationship to the mechanical resistance, resistance to the abrasion and incrustation degree.

\section{Acknowledgments}

The authors are grateful to Capes and CNPq/Brazil for funding this work as well as to the Centre of Technology in Materials-SC/ Brazil.

\section{References}

1. Ashrae Fundamentals. Thermal Comfort. Atlanta; 1997.

2. Aivazov MI, Domashnev IA. Influence of porosity on the conductivity of hot pressed titanium nitride specimens. Poroshkovaya Metallurgiya (Soviet P/M and Metal Ceramics). 1968; 8(9):51-54.

Table 5. Measured and Theoretical Foot/Contact Temperatures.

\begin{tabular}{lcccc}
\hline Samples & $\mathrm{T}_{\text {sun }}\left({ }^{\circ} \mathrm{C}\right)$ & $\mathrm{T}_{\text {foot }}\left({ }^{\circ} \mathrm{C}\right)$ & $\varepsilon_{\text {foot }}\left(\mathrm{Ws}^{0,5} / \mathrm{m}^{2} \mathrm{~K}\right)$ & $\mathrm{T}_{\text {contact theoretical }}\left({ }^{\circ} \mathrm{C}\right)$ \\
\hline M & 56.3 & 34 & 1359 & 49.4 \\
MAR 40 & 55.0 & 34 & 898 & 42.8 \\
\hline
\end{tabular}


3. British standards institution (BSI) PD 6504 of 1983 on Medical information on human reaction to skin contact with hot surfaces.

4. Fanger PO. Thermal Comfort. New York: McGraw-Hill Book Company; 1970.

5. Incropera FP, De Witt DP. Fundamentos de Transferência de Calor e de Massa. 3 ed. Rio de Janeiro: Guanabara Koogan; 1992.

6. ISO 8301 of 1991 on Standard Test Method for Steady-State Heat Flux Measurements and Thermal Transmission Properties by Means of the Heat Flow Meter Apparatus. Geneve. Switzerland.

7. Lemos AF, Ferreira JMF. Novo Método de Preparação de Corpos Macroporosos de Cordierite. Anais do $45^{\circ}$ Congresso Brasileiro de Cerâmica; 30 de Maio a 2 de Junho de 2001; Florianópolis: Universidade Federal de Santa Catarina; 2001
8. Rhee SK. Porosity-Thermal Conductivity Correlations for Ceramic Materials. Materials Science and Engineering. 1975; 20(1):89-93.

9. Secretaria de Segurança e Saúde no Trabalho do Ministério do Trabalho (SSST/MTb) NR-15 de 08 de junho de 1978 em Atividades e Operações Insalubres. Brasília. Brasil.

10. Sugawara A, Yoshizawa. An Experimental Investigation on the Thermal Conductivity of Consolidated Porous Materials. Journal of Applied Physics. 1962; 33(10):3135-3138.

11. Xavier AAP. Predição de conforto térmico em ambientes internos com atividades sedentárias-Teoria física aplicada à estudos de campo. [Tese de Doutorado]. Florianópolis: Universidade Federal de Santa Catarina; 2000; p. 251. 